\title{
CAPÍTULO 16: ASPECTOS ÉTICOS EM PESQUISA: UM ESTUDO SOBRE AS EXIGÊNCIAS E PROCEDIMENTOS DO COMITÊ DE ÉTICA EM PESQUISA DA UNIVERSIDADE DE PERNAMBUCO
}

\author{
CAPÍTULO 16: ASPECTOS ÉTICOS EN LA INVESTIGACIÓN: UN ESTUDIO \\ SOBRE LOS REQUISITOS Y PROCEDIMIENTOS DEL COMITÉ DE ÉTICA EN LA \\ INVESTIGACIÓN DE LA UNIVERSIDAD DE PERNAMBUCO
}

\section{CHAPTER 16: ETHICAL ASPECTS IN RESEARCH: A STUDY ON THE REQUIREMENTS AND PROCEDURES OF THE ETHICS COMMITTEE IN RESEARCH OF THE UNIVERSITY OF PERNAMBUCO}

\begin{abstract}
Derek Luiz Alves dos Santos ${ }^{1}$; Moisés da Silva Gomes ${ }^{2}$; José Luiz Alves ${ }^{3}$; Wilde Valéria Alves dos Santos ${ }^{4}$; Marisa Marinho Fernandes Viana ${ }^{5}$
\end{abstract}

DOI : https://doi.org/10.31692/978-65-88970-03-4.209-214

\section{INTRODUÇÃO}

O âmbito acadêmico é contextualmente propício ao desenvolvimento de estudos científicos, tendo oportunamente os respectivos estudantes, contato com métodos e técnicas de pesquisa científica, esses, voltados para o desenvolvimento de trabalhos de interesse da sociedade como um todo.

Tratando-se dos estudantes dos cursos stricto sensu, observa-se como requisito para obtenção de títulos, o desenvolvimento de estudos que, a partir de projetos de pesquisa devidamente qualificados, resultem em: dissertações, teses e/ou artigos.

Neste sentido, torna-se importante entender o que se é exigido pelos Comitês de Ética em Pesquisa (CEP's), antes da submissão de novos projetos na Plataforma Brasil. E daí surgese à seguinte indagação: Quais os aspectos éticos e procedimentos burocráticos em pesquisa, exigidos e/ou recomendados pelo CEP da Universidade de Pernambuco - UPE? Presupõe-se que a instituição dada o seu caráter público, oferte desburocratizado acesso a dados e informações, sobre o respectivo assunto, isso, de modo a orientar a toda comunidade acadêmica e sociedade.

Este estudo faz-se jus a uma revisão bibliografica que viabiliza a aplicação dos procedimentos ora apresentados, bem como, a análise de políticas públicas.

\footnotetext{
${ }^{1}$ Mestre em GDLS pela Universidade de Pernambuco - UPE, Instituto Federal de Pernambuco - IFPE, derek.alves@ recife.ifpe.edu.br

${ }^{2}$ Mestre em GDLS, Universidade de Pernambuco - UPE, msgo7@ hotmail.com

${ }^{3}$ Doutor, Professor da Universidade de Pernambuco - UPE, luiz.alves@ upe.br

${ }^{4}$ Especialista, Professora da Rede Municipal de Parnamirim/RN, wildevaleria@ hotmail.com

${ }^{5}$ Especialista, Faculdade Mantenense dos Vales Gerais - INTERVALE, top.marisa@ hotmail.com 


\section{FUNDAMENTAÇÃO TEÓRICA}

Para Chaui (2010) o campo ético é assim, constituído por valores e pelas obrigações que formam o conteúdo das condutas morais, isto é, as virtudes. Ser ético, portanto, é agir dentro dos padrões, executando os valores definidos pela sociedade.

Toda profissão define-se a partir de um corpo de práticas que busca atender demandas sociais, norteado por elevados padrões técnicos e pela existência de normas éticas que garantam a adequada relação de cada profissional com seus pares e com a sociedade como um todo. (CFP, 2005. p.5)

Conforme Brasil (s.d.), em 1988 o Conselho Nacional de Saúde - CNS elaborou a Resolução $n^{\circ} 01 / 88$, que foi a primeira tentativa de normatizar um código de ética médica para o país. Em 1996 o CNS juntamente com setores da comunidade científica, governo e sociedade civil aprovaram um novo, a Resolução 196/1996. Nela estão a principais diretrizes para apreciação da ética nos projetos de pesquisas envolvendo seres humanos no Brasil. A Resolução 196/96 também criou um sistema nacional para acompanhamento desses projetos, instituindo a Comissão Nacional de Ética em Pesquisa - CONEP e criando ainda os Comitês de Ética em pesquisas (CEP'S).

“Para obtenção da Certificação junto à CONEP, os CEP's devem atender a Resolução 370/2007 do CNS". (UPE, 2018, s.p.)

O Comitê de Ética em Pesquisa da Universidade de Pernambuco (CEP-UPE) foi institucionalizado em 1998 em atenção às recomendações do Conselho Nacional de Saúde/Ministério da Saúde relativas à regulamentação de pesquisas com seres humanos. Os CEP's respondem à CONEP, vinculada ao CNS e órgãos superiores que fiscalizam e coordenam suas atividades (UPE, 2018).

No quadro 1, contextualiza-se melhor os CEP's, apresentando-se uma cronologia de resoluções atreladas ao objeto.

Quadro 1: Caracterização dos Comitês de Ética em Pesquisa

\section{MISSÃO / ATRIBUIÇÕES}

A missão do CEP é salvaguardar os direitos e a dignidade dos sujeitos da pesquisa. Além disso, o CEP contribui para a qualidade das pesquisas e para a discussão do papel da pesquisa no desenvolvimento institucional e no desenvolvimento social da comunidade. Contribui ainda para a valorização do pesquisador que recebe o reconhecimento de que sua proposta
Resolução $\mathbf{n}^{\mathbf{0}}$ 1.098/1983 CFM - Recomendações orientando médicos em pesquisa com seres humanos;

Resolução $\mathbf{n}^{0}$ 240/1997 CNS/MS - Definição do termo USUÁRIO;

Resolução no 251/1997 CNS/MS - Pesquisa com novos fármacos, medicamentos, vacinas e testes diagnósticos;

Resolução no 292/1999 CNS/MS - Pesquisas coordenadas no exterior ou com participação estrangeira e pesquisa que envolva 
é eticamente adequada.

O CEP é responsável pela avaliação e acompanhamento dos aspectos éticos de todas as pesquisas envolvendo seres humanos. Este papel está bem estabelecido nas diversas diretrizes éticas internacionais (Declaração de Helsinque, Diretrizes Internacionais para as Pesquisas Biomédicas envolvendo Seres Humanos - CIOMS) e brasileiras (Res. CNS n ${ }^{\circ}$ 196/96 e complementares).

Cabe à instituição onde se realizam pesquisas, a constituição do CEP.

$\mathrm{O}$ CEP, ao emitir parecer, independentemente e consistente, contribui ainda para o processo educativo dos pesquisadores da instituição e dos próprios membros do comitê.

$\mathrm{O}$ CEP tem ainda função consultiva e de promoção da formação continuada dos pesquisadores da instituição, oportunizando discussões dos aspectos éticos das pesquisas em seres humanos e de interesse da comunidade. Dessa forma, deve promover atividades, tais como seminários, palestras, jornadas, cursos e estudo de protocolos de pesquisa. remessa de material biológico para o exterior;

Resolução no 301/2000 CNS/MS - Que se mantenha inalterado o item II.3 da Declaração de Helsinque;

Resolução no 303/2000 CNS/MS - Área temática especial "Reprodução Humana";

Resolução no 304/2000 CNS/MS - Área temática especial "Populações Indígenas";

Resolução no 340/2004 CNS/MS - Área temática especial "Genética Humana";

Resolução no 346/2005 CNS/MS - Projetos de pesquisa multicêntricos;

Resolução $\mathbf{n}^{\circ}$ 347/2005 CNS/MS - Regulamentar o armazenamento e utilização de material biológico humano no âmbito de projeto de pesquisa;

Resolução no 404/2008 CNS/MS - Responsabilidade do CNS na proteção da integridade do sujeito de pesquisa;

Resolução no 1.885/2008 CFM - É vedado ao médico participar de pesquisa envolvendo o uso do Placebo, quando houver tratamento disponível eficaz já conhecido.

Resolução no 466/2012 CNS/MS - Diretrizes e Normas Regulamentadoras de pesquisa envolvendo seres humanos;

Resolução $\mathbf{n}^{\mathbf{0}}$ 510/2016 CNS/MS - Normas Aplicáveis a Pesquisas em Ciências Humanas e Sociais.

Fonte: Própria (2020).

Nota: Baseado em UPE (2019).

De acordo com a Resolução $n^{\circ} 466 / 12$ e a Resolução n. 510/16, toda pesquisa envolvendo seres humanos deve ser submetida à apreciação de um CEP. Assim, o pesquisador somente poderá iniciar a sua pesquisa, proceder com a coleta dos dados, caso obtenha aprovação do Comitê de Ética em Pesquisa. Desta maneira, todas as pesquisas envolvendo seres humanos devem ser analisadas pelo Sistema CEP/CONEP. No art. 23 da Resolução 510/2016, enfatiza-se que os projetos de pesquisa serão submetidos na "Plataforma Brasil" para sua avaliação ética, tipificação de risco e tramitação dos protocolos. O sistema permite, ainda, o acesso pela sociedade, aos dados públicos, de todas as pesquisas aprovadas.

A Plataforma Brasil é uma base nacional e unificada de registros de pesquisas envolvendo seres humanos para todo o sistema CEP/Conep. Ela permite que as pesquisas sejam acompanhadas em seus diferentes estágios - desde sua submissão até a aprovação final pelo CEP e pela Conep, quando necessário. (BRASIL, s.d., n.p.)

Para os fins da Resolução 510/2016, no art. $2^{\circ}$, adota-se os seguintes termos e definições: 
benefícios; IV - confidencialidade; V - consentimento livre e esclarecido; VI informações de acesso público; VII - dano material; VIII - dano imaterial; IX discriminação; X - esclarecimento; XI - estigmatização; XII - etapas preliminares de uma pesquisa; XIII - participante da pesquisa; XIV - pesquisa de opinião pública; XV - pesquisa encoberta; XVI - pesquisa em ciências humanas e sociais; XVII pesquisador responsável; XVIII - preconceito; XIX - privacidade; XX - processo de consentimento e de assentimento; XXI - protocolo de pesquisa; XXII - registro do consentimento ou do assentimento; XXIII - relatório final; XXIV - ressarcimento; XXV - risco da pesquisa; XXVI - vulnerabilidade.

No quadro 2, consta alguns termos e definições essencialmente importantes, contidos no arts. $2^{\circ}, 12^{\circ}$ e $14^{\circ}$ da respectiva Resolução 510/2016.

Quadro 2: Principais documentos exigidos pela Plataforma Brasil /CEP-UPE

TERMO DE CONFIDENCIALIDADE: É a garantia do resguardo das informações dadas em confiança e a proteção contra a sua revelação não autorizada, resguardada no Art. $2^{\circ}$, inciso IV.

INSTRUMENTO DE COLETA DE DADOS: O instrumento de coleta de dados seja ele questionário, formulário, roteiro de perguntas, etc., pormenorizadamente descrito na Metodologia do projeto e informado no Termo de Consentimento Livre e Esclarecido deve assegurar ao pesquisado o direito de recusa em respondê-lo na ocorrência de questionamentos que gerem qualquer tipo de constrangimento ou desconforto. E fundamental que o instrumento a ser utilizado já tenha sido validado e utilizado no Brasil. Na hipótese de instrumentos a serem desenvolvidos especificamente para a pesquisa, verificar a necessidade de um ESTUDO PILOTO, para teste da validade do instrumento. Em nenhuma hipótese o instrumento deve ser impresso em papel timbrado.

TERMO DE CONSENTIMENTO LIVRE E ESCLARECIDO - TCLE: Toda pesquisa envolvendo seres humanos necessita do consentimento livre e esclarecido do entrevistado. O Registro do Consentimento e do Assentimento é o meio pelo qual é explicitado o consentimento livre e esclarecido do participante ou de seu responsável legal, sob a forma escrita, sonora, imagética.

JUSTIFICATIVA DA NÃO APRESENTAÇÃO DO TCLE: O Art. 14 explica que quando for inviável a realização do processo de Consentimento Livre e Esclarecido, a dispensa desse processo deve ser justificadamente solicitada pelo pesquisador responsável ao Sistema CEP/CONEP para apreciação. Em seu $\S$ $3^{\circ}$ estabelece que: a dispensa do Registro do Consentimento deverá ser avaliada e aprovada pelo sistema CEP/CONEP.

TERMO DE ASSENTIMENTO: O Termo de assentimento do participante e o consentimento livre e esclarecido, por meio dos representantes legais do participante da pesquisa, preservado o direito à informação e à autonomia do participante, de acordo com a sua capacidade, está previsto no Parágrafo único, do art. 12.

CARTA DE ANUÊNCIA: Trata-se de documento preliminar que autoriza a pesquisa no referido campo onde ocorrerá a coleta de dados.

TERMO DE CONCESSÃO: O Termo de Concessão deve ser elaborado em papel timbrado da instituição onde será realizada a coleta de dados, devendo conter nome endereço e CNPJ da instituição, assinatura e carimbo da pessoa responsável pelo setor onde serão coletados os dados.

CURRÍCULO LATTES: Currículo Lattes do pesquisador principal e dos demais pesquisadores participantes (só há necessidade de anexar a primeira página onde consta o endereço da Plataforma Lattes e a data da última atualização). O currículo deve estar atualizado no mínimo em 90 dias anteriores a data de avaliação do projeto no CEP (verificar calendário).

FOLHA DE ROSTO: A Folha de Rosto é elaborada a partir do preenchimento das telas na Plataforma Brasil. Após o preenchimento de todos os dados necessários, aparecerá uma informação "IMPRIMIR FOLHA DE ROSTO”. Com a Folha de Rosto impressa, recolher as devidas assinaturas e carimbos para anexá-la ao projeto.

PARECER DO PROJETO MÃE: O parecer do Projeto mãe diz respeito que o Projeto derivado de uma pesquisa anterior deve ter incluída uma cópia do Parecer de Aprovação do Comitê de Ética em Pesquisa que 
julgou o projeto original.

Fonte: Própria (2020).

Nota: Baseado em UPE (2019).

\section{METODOLOGIA}

Trata-se de uma pesquisa de natureza aplicada, pela geração de conhecimentos dirigidos à solução de problemas específicos, neste caso, a dúvida de pós-graduandos stricto sensu, quanto à necessidade da inserção de aspectos éticos em seus projetos de pesquisa, a partir de esclarecimentos sobre quais são as exigências e procedimentos eventualmente necessários para a aprovação de seus respetivos projetos.

A abordagem é qualitativa e direcionada a atividade acadêmica de pesquisa, sendo assim classificada, por retratar e possibilitar uma análise com maior profundidade contextual. Ademais, possui um enfoque exploratório-descritivo, uma vez que se busca a aproximação com o objeto na perspectiva de levantar as suas características, e pela tentativa de melhor conhecê-las e contextualizá-las, respectivamente.

O procedimento técnico de pesquisa se deu a partir da seleção e, consequentemente, pela busca de artigos científicos realizada pelas plataformas eletrônicas: Capes, Scielo e Google Acadêmico, bem como pela busca na internet de artigos informativos, por meio de buscadores, bem como, pela visita a páginas eletrônicas governamentais, relacionadas ao tema, afim de realizar-se uma revisão bibliográfica, bem como análise documental.

O campo de pesquisa foi a UPE e a coleta e tratamento de dados e informações se deu por meio de levantamento e fichamento de bibliografia e de documentos.

\section{RESULTADOS E DISCUSSÃO}

Nota-se no contexto da UPE a existência de um CEP, alinhado a CONEP, consequentemente, a toda a legislação pertinente, e, em especial, as resoluções do Observa-se ainda que assim como órgãos governamentais competentes, a UPE disponibiliza publicamente informações claras a respeito do tema e dos procedimentos ora exígíveis e recomendáveis, concernentes ao ato de submissão de projetos para análise e parecer, visando o resguardo de seres humanos quanto a possíveis danos a serem causados, bem como, a promoção da educação dos pesquisadores nos aspectos éticos em pesquisa (UPE, 2019).

As referidas informações disponibilizadas em seu web site (institucional) 
disponibilizado nas "referências" do presente trabalho, são de grande relevância, uma vez ser o ponto de partida para um adequado e coerente trabalho juntamente aos sujeitos e instituições, que oportunamente, serão submetidos a estudos científicos.

\section{CONCLUSÕES}

Ao se trabalhar com pesquisas que envolvem serem humanos, algumas questões éticas devem ser analisadas. O pesquisador como qualquer outro profissional, deve trabalhar com o conhecimento sabendo que as suas ações poderão afetar a vida de instituições ou de pessoas.

$\mathrm{Na}$ pesquisa científica, alguns procedimentos, se mal utilizados, poderão eventualmente prejudicar tanto a integridade pessoal dos pesquisadores, quanto da sociedade em geral, no que concerne às informações obtidas. $E$, embora a ciência necessite constantemente progredir, ela deve observar as questões éticas envolvidas, impondo certos limites, isso, principalmente quando essas envolverem seres humanos.

Sendo assim, cabe aos pesquisadores atenção a essas questões, procurando estarem atualizados quanto à legislação pertinente e as recomendações disponibilizadas, de modo tal, a sempre seguir um caminho ético, empático, técnico e responsável.

\section{REFERÊNCIAS}

BRASIL. Ministério da Saúde. Plataforma Brasil. Disponível em: <http://plataformabrasil.saude.gov.br/login.jsf;jsessionid=90488BE448B1A7EBA805E93D2 D1C9E0A.server-plataformabrasil-srvjpdf132>. Acesso em: 28 de agosto de 2019.

. Ministério da Saúde. Resolução no 466, de 12 de dezembro de 2012. Dispõe sobre diretrizes e normas regulamentadoras de pesquisas envolvendo seres humanos. Disponível em:<https://bvsms.saude.gov.br/bvs/saudelegis/cns/2013/res0466_12_12_2012.html>. Acesso em: 28 de agosto de 2019.

Ministério da Saúde. Resolução no 510, de 07 de abril de 2016. Dispõe sobre Normas Aplicáveis a Pesquisas em Ciências Humanas e Sociais. Disponível em: <https://bvsms.saude.gov.br/bvs/saudelegis/cns/2016/res0510_07_04_2016.html>. em: 28 de agosto de 2019.

CHAUI, Marilena. Convite à Filosofia. $14^{\text {a }}$ Ed. $1^{\text {a }}$ impressão. Editora Afiliada, 2010.

CONSElho Federal De PSiCOlOGiA - CFP. Código de Ética Profissional do Psicólogo. Brasília, agosto de 2005.

UNIVERSIDADE DE PERNAMBUCO - UPE. Comitê de Ética em Pesquisa - CEP. Disponível em: <http://www.upe.br/cep.html〉. Acesso em: 28 de agosto de 2019. 